\title{
Gene Transfer into Hepatocytes Using Asialoglycoprotein Receptor Mediated Endocytosis of DNA Complexed with an Artificial Tetra-Antennary Galactose Ligand
}

\author{
Christian Plank, Kurt Zatloukal, Matt Cotten, Karl Mechtler, and Ernst Wagner* \\ Research Institute of Molecular Pathology, Dr. Bohr-Gasse 7, A-1030 Vienna, Austria. Received July 14, 1992
}

\begin{abstract}
We have constructed an artificial ligand for the hepatocyte-specific asialoglycoprotein receptor for the purpose of generating a synthetic delivery system for DNA. This ligand has a tetra-antennary structure, containing four terminal galactose residues on a branched carrier peptide. The carbohydrate residues of this glycopeptide were introduced by reductive coupling of lactose to the $\alpha$ - and $\epsilon$-amino groups of the two $\mathrm{N}$-terminal lysines on the carrier peptide. The $\mathrm{C}$-terminus of the peptide, containing a cysteine separated from the branched $\mathrm{N}$-terminus by a 10 amino acid spacer sequence, was used for conjugation to 3-(2-pyridyldithio)propionate-modified polylysine via disulfide bond formation. Complexes containing plasmid DNA bound to these galactose-polylysine conjugates have been used for asialoglycoprotein receptor-mediated transfer of a luciferase gene into human (HepG2) and murine (BNL CL.2) hepatocyte cell lines. Gene transfer was strongly promoted when amphipathic peptides with $\mathrm{pH}$-controlled membrane-disruption activity, derived from the $\mathrm{N}$-terminal sequence of influenza virus hemagglutinin HA-2, were also present in these DNA complexes. Thus, we have essentially borrowed the small functional domains of two large proteins, asialoglycoprotein and hemagglutinin, and assembled them into a supramolecular complex to generate an efficient gene-transfer system.
\end{abstract}

\section{INTRODUCTION}

During the last few years gene-transfer methods have been developed that adopt natural receptor-mediated endocytosis pathways for the delivery of DNA into eukaryotic cells. Ligands for cellular receptors, such as transferrin $(1,2)$, viral proteins $(3)$, insulin bound to albumin (4), or asialoorosomucoid $(5,6)$ have been successfully used for the import of DNA molecules. For this purpose these ligands have been conjugated to DNAbinding compounds, such as a polycation or an intercalating agent. Incubating DNA with these protein conjugates generates ligand-coated DNA which can bind receptors on the cell surface and is subsequently internalized. Small synthetic, rationally designed compounds that bind specifically to a cellular receptor may be useful, well-defined alternatives for large protein ligands.

In this paper we describe the synthesis of polylysine conjugates containing an artificial ligand for the asialoglycoprotein receptor (7). This hepatocyte-specific receptor recognizes exposed galactose on serum glycoproteins that have lost the terminal sialic acids and rapidly removes these glycoproteins from the circulation to the liver. The artificial ligand we designed displays four galactoside residues on a branched carrier peptide possessing a C-terminal cysteine as a ligation site for coupling to the DNA-binding polycation polylysine. Using this proteinfree, synthetic polylysine conjugate, luciferase gene transfer into cultured hepatocytes is possible with an efficiency similar to that achieved with a natural ligand, asialofetuin, conjugated to polylysine. One limit to receptor-mediated gene delivery may be the accumulation of the delivered DNA complexes in intracellular vesicles $(2,3,8)$. To overcome this barrier, we have developed strategies that utilize the endosome disruption activity of either defective adenovirus particles $(9,10)$ or synthetic, amphipathic peptides (11), derived from the $\mathrm{N}$-terminus of the influenza virus hemagglutinin HA-2 protein (12). Further goals of this work have been to prepare DNA complexes containing both the synthetic galactose-ligand and the amphipathic peptides, and to subsequently investigate whether these protein-free DNA complexes have improved gene transfer efficiencies.

\section{EXPERIMENTAL PROCEDURES}

Materials and Conjugates. The DNA plasmid pCMVL, containing the Photinus pyralis luciferase gene under control of the cytomegalovirus enhancer/promoter, was prepared by removing the BamHI insert of the plasmid pSTCX556 (13), treating the plasmid with Klenow fragment, and ligating with the HindIII/SspI and Klenowtreated fragment from the plasmid pRSVL (14), which contains the sequence coding for luciferase. Human transferrin-poly(L-lysine) conjugates with an average chain length of 190 lysines ( $\left.T f p L 190^{1}\right)$ or 290 lysines (TfpL290) were prepared as described (15). Mouse transferrin-poly(L-lysine) conjugates (mTfpL290) were synthesized using the method described in ref 1 . Conjugate InflupL, containing the peptide derived from influenza virus hemagglutinin (Gly-Leu-Phe-Glu-Ala-Ile-Ala-Gly-Phe-IleGlu-Asn-Gly-Trp-Glu-Gly-Met-Ile-Asp-Gly-Gly-GlyCys) coupled to polylysine pLys 300 , was synthesized as described in ref 11 . Synthesis of $\mathrm{N}^{\mathrm{t}}$-lactosylated polylysine (pLys-lactose) was performed as follows: to a solution of $16.5 \mathrm{mg}(0.44 \mu \mathrm{mol})$ of $\mathrm{pLys}_{200}$, acetate salt, in $0.46 \mathrm{~mL}$ of $100 \mathrm{mM}$ sodium acetate (pH 5.0) was added $90 \mathrm{mg}(0.26$ mmol) of lactose (Sigma), which dissolved upon agitating within $30 \mathrm{~min}$ at $37^{\circ} \mathrm{C}$. The solution was kept at this temperature while four $3-\mathrm{mg}$ portions of sodium cyanoborohydride were added in about 10 -h intervals. The reaction mixture was left for an additional $21 \mathrm{~h}$ at $37^{\circ} \mathrm{C}$; then $15 \mu \mathrm{L}$ of acetic acid was added, and the reaction

${ }^{1}$ Abbreviations used: TfpL, transferrin-poly(L-lysine) conjugate; $\mathrm{AFpL}$, asialofetuin-poly(L-lysine) conjugate; $\mathrm{pLys}_{200}$ and $\mathrm{pLys}_{290}$, poly (L-lysine) with an average chain length of 200 or 290 lysine monomers; HEPES, 4-(2-hydroxyethyl)-1-piperazineethanesulfonic acid; HBS, HEPES-buffered saline (150 mM NaCl, 20 mM HEPES, pH 7.3). 
mixture was subjected to gel filtration (Sephadex G25$\mathrm{PD} 10$ ) in $100 \mathrm{mM}$ sodium acetate (pH 5.0). The productcontaining fraction (identified by ninhydrin assay and staining with anisaldehyde after spotting $1-\mu \mathrm{L}$ samples on TLC plates) was dialyzed against $20 \mathrm{mM}$ sodium acetate overnight and then against $0.05 \%$ acetic acid. Lyophilization gave $26.5 \mathrm{mg}$ of pLys 200 , acetate salt, with about $75-80 \%$ of the $N^{\epsilon}$-lysine amino groups lactosylated, as determined by ninhydrin analysis and NMR analysis $\left[{ }^{1} \mathrm{H}\right.$ $\operatorname{NMR}\left(\mathrm{D}_{2} \mathrm{O}, 250 \mathrm{MHz}\right.$, solvent suppression): $\delta(\mathrm{ppm})=$ 4.51 (d, $J=7.2 \mathrm{~Hz}$, galactose-1H), 4.22-4.34 (lysine $\alpha-\mathrm{H}$ ), 4.1-4.22 (sugar $H$ ), 2.9-4.0 (lysine $\epsilon-H$ and sugar $H$ ), 1.91 (acetate, $\mathrm{CH}_{3}$ ), 1.1-2.0 (aliphatic $\mathrm{CH}_{2}$ of lysine)].

Assays. The amount of dithiopyridine linkers in modified asialofetuin or polylysine was determined after reduction of an aliquot with dithiothreitol followed by absorption measurement of released pyridine-2-thione at $340 \mathrm{~nm}$. The polylysine content of fractions was estimated spectrophotometrically by ninhydrin assay. The amount of free mercapto groups in modified polylysine or peptides was determined using 5,5'-dithiobis(2-nitrobenzoic acid) (16) and measurement at $412 \mathrm{~nm}$. The asialofetuin content of fractions was determined by UV measurement at 280 $\mathrm{nm}$ and correction of the value (where necessary) by substraction of the corresponding UV absorption of dithiopyridine or buffer at $280 \mathrm{~nm}$. Lactosylation was monitored by staining with anisaldehyde reagent $(p$ anisaldehyde/sulfuric acid/ethanol, 1/1/18) on TLC plates (silica gel), by ${ }^{1} \mathrm{H}-\mathrm{NMR}$ analysis, and/or spectrophotometrically by the anthron assay (17) using lactosylated polylysine as standard.

Asialofetuin-Polylysine Conjugate Synthesis. Asialofetuin-polylysine conjugate (AFpL) was synthesized by coupling asialofetuin to polylysine via disulfide bonds after modification of asialofetuin with the bifunctional reagent succinimidyl 3-(2-pyridyldithio)propionate (SPDP, Pharmacia) in a similar fashion as described (1). To a solution of $100 \mathrm{mg}(2.2 \mu \mathrm{mol})$ of asialofetuin (Sigma) in $4 \mathrm{~mL}$ of 100 mM HEPES buffer, pH 7.9, was added $330 \mu \mathrm{L}$ of a $15 \mathrm{mM}$ ethanolic solution of SPDP $(5.0 \mu \mathrm{mol})$ with vigorously mixing. After $1 \mathrm{~h}$ at room temperature, purification was performed by gel filtration (Sephadex G25; $100 \mathrm{mM}$ HEPES buffer, $\mathrm{pH} 7.9$ ) to give $5 \mathrm{~mL}$ of a solution of 1.4 $\mu \mathrm{mol}$ of asialofetuin modified with $2.25 \mu \mathrm{mol}$ of dithiopyridine linker. This solution was mixed under an argon atmosphere with a solution of $0.33 \mu \mathrm{mol}$ of poly(L-lysine) with an average chain length of 190 lysine monomers (pLys $\left.{ }_{190}\right)$, modified with $1.07 \mu \mathrm{mol}$ of 3 -mercaptopropionate groups as described in ref 1 , in $6.5 \mathrm{~mL}$ of $200 \mathrm{mM}$ HEPES buffer, $\mathrm{pH} 7.6$. The reaction mixture was kept for $24 \mathrm{~h}$ at room temperature. Conjugates were isolated from the reaction mixture by cation-exchange chromatography (Mono S column HR 10/10, Pharmacia; gradient elution with buffer A, $50 \mathrm{mM}$ HEPES, pH 7.9, and buffer $B$, buffer A plus $3 \mathrm{M} \mathrm{NaCl}$ ). Sodium chloride was added to the reaction mixture (final concentration $0.6 \mathrm{M}$ ) before loading the column, and the gradient was started at this salt concentration. The product was eluted at a $\mathrm{NaCl}$ concentration of ca. $1.5 \mathrm{M}$. After dialysis against HBS, conjugates containing $0.24 \mu \mathrm{mol}$ of $\mathrm{pLys}_{190}$ modified with $0.52 \mu \mathrm{mol}$ asialofetuin were obtained.

Synthesis of Tetragalactose-Peptide-Polylysine Conjugate (gal)4pL. (A) Lactosylated Peptide $1 b$. Freeze-dried, branched peptide $1 \mathrm{a}(3.5 \mathrm{mg}, 1.92 \mu \mathrm{mol})$ with the sequence $\alpha, \epsilon$-(Lys) ${ }_{2}$-Lys-Gly-(Ser-Gly-Gly) ${ }_{3}-[S-$ (2-pyridylthio) ]Cys, synthesized by the Fmoc procedure (18, 19) using an Applied Biosystems $431 \mathrm{~A}$ peptide synthesizer and $\alpha, \epsilon$-bis (Fmoc)-protected lysine (Bachem), was treated with a solution of $7.85 \mathrm{mg}$ ( $23 \mu \mathrm{mol})$ of lactose in $40 \mu \mathrm{L}$ of $10 \mathrm{mM}$ aqueous sodium acetate, pH 5 at $37^{\circ} \mathrm{C}$. To the solution were added four $0.6 \mathrm{mg}(10 \mu \mathrm{mol})$ portions of sodium cyanoborohydride at 10 -h intervals. After a total of $64 \mathrm{~h}$ at $37^{\circ} \mathrm{C}, 0.5 \mathrm{~mL}$ of HEPES, $\mathrm{pH} 7.3$, and $15 \mathrm{mg}$ of dithiothreitol were added. After $30 \mathrm{~min}$, fractionation by gel filtration (Sephadex G10,12 $\times 130 \mathrm{~mm}$, eluent $20 \mathrm{mM}$ $\mathrm{NaCl}$ ) under argon yielded a 3.6-mL solution of lactosylated peptide $1 \mathrm{~b}$ in the free mercapto form ( $1.73 \mu \mathrm{mol}$, according to an assay with Ellman's reagent, an $84 \%$ yield). Samples of the modified peptide showed a color reaction with anisaldehyde, but no color reaction with ninhydrin; this is consistent with the assumption that all four $\mathrm{N}$-terminal amino groups have been lactosylated. ${ }^{1} \mathrm{H}$ NMR analysis $\left(\mathrm{D}_{2} \mathrm{O}, 250 \mathrm{MHz}\right.$, solvent suppression) demonstrated that the group of five $\alpha$-H signals, $\delta$ (ppm) $=4.58$ ( $1 \mathrm{H}, \mathrm{Cys}), 4.52$ ( $3 \mathrm{H}, 3 \mathrm{Ser}), 4.35$ ( $1 \mathrm{H}, \mathrm{Lys})$, found in the spectrum of the precursor peptide is overlaid by the signal of four galactose-1H protons at $4.51 \mathrm{ppm}(4 \mathrm{H})$. Time-of-flight mass spectrum performed with a Bio Ion ${ }^{252}$ Cf PD-MS instrument (Uppsala, Sweden) showed a major mass peak of $2473\left(\mathrm{MH}^{+}\right.$of product $1 \mathrm{~b}$ ) and a minor peak of 2146 (presumably traces of tris-lactosylated peptide).

(B) 3-Dithiopyridinepropionate-Modified Polylysine 2. To a gel-filtered solution of $0.60 \mu \mathrm{mol}$ of $\mathrm{pLys}_{290}$ (hydrobromide, Sigma) in $1.2 \mathrm{~mL}$ of $100 \mathrm{mM}$ HEPES buffer, $\mathrm{pH} 7.9$, was added $400 \mu \mathrm{L}$ of a $15 \mathrm{mM}$ ethanolic solution of SPDP $(6.0 \mu \mathrm{mol})$ with vigorous mixing. One hour later $500 \mu \mathrm{L}$ of $1 \mathrm{M}$ sodium acetate, $\mathrm{pH} 5$, was added; gel filtration (Sephadex G25, 100 mM sodium acetate, pH 5) yielded a $2.4 \mathrm{~mL}$ solution of 2 , containing $0.56 \mu \mathrm{mol}$ of pLys $_{290}$ modified with $5.77 \mu \mathrm{mol}$ of dithiopyridine linker.

(C) Conjugation of Peptide with Polylysine. Conjugates were prepared by mixing $1.5 \mu \mathrm{mol}$ of lactosylated peptide $1 \mathrm{~b}$ in $3 \mathrm{~mL}$ of $20 \mathrm{mM} \mathrm{NaCl}$ with $0.146 \mu \mathrm{mol}$ of modified polylysine 2 in $620 \mu \mathrm{L}$ of $100 \mathrm{mM}$ sodium acetate buffer, pH 5, under an argon atmosphere. After the addition of $100 \mu \mathrm{L}$ of $2 \mathrm{M}$ HEPES, pH 7.9, the reaction mixture was kept for $18 \mathrm{~h}$ at room temperature. The salt concentration was brought to $0.66 \mathrm{M}$ by addition of $\mathrm{NaCl}$, and conjugates were isolated by cation-exchange chromatography (Pharmacia Mono S column HR 5/5; gradient elution with buffer A, 50 mM HEPES, pH 7.3, and buffer B, buffer A plus 3 $\mathrm{M} \mathrm{NaCl}$ ). The product fractions were eluted at salt concentrations around 1.2-1.8 $\mathrm{M}$ and pooled. After

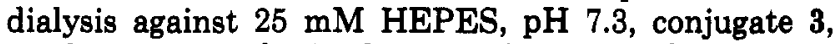
"(gal) $4 \mathrm{pL}$ ", was obtained, containing $49 \mathrm{nmol}$ of pLys 290 modified with ca. $380 \mathrm{nmol}$ of ligand moieties (i.e. $1.5 \mu \mathrm{mol}$ of lactosamine groups).

Cells and Transfections. HepG2 cells (ref 20, a kind gift of Prof. M. Spiess, Basle) were grown in DMEM plus $10 \%$ FCS, 100 units $/ \mathrm{mL}$ penicillin, $100 \mu \mathrm{g} / \mathrm{mL}$ streptomycin, and $2 \mathrm{mM}$ glutamine in $25 \mathrm{~cm}^{2}$ flasks. The mouse embryonic liver cell line BNL CL.2 (ATCC TIB 73; ref 21) was grown in 6-cm plates in high glucose DMEM $(0.4 \%$ glucose) supplemented with $10 \%$ heat-deactivated FCS, with 100 units $/ \mathrm{mL}$ penicillin, $100 \mu \mathrm{g} / \mathrm{mL}$ streptomycin, and $2 \mathrm{mM}$ glutamine at $37^{\circ} \mathrm{C}$ in a $5 \% \quad \mathrm{CO}_{2}$ atmosphere. Transfections were performed at a density of $300000-$ 400000 cells per flask (or plate). Before transfection, cells were supplied with fresh serum-supplemented medium. The cells were harvested for the luciferase assay (3) $24 \mathrm{~h}$ after transfection. Values shown in the figures represent the total luciferase activity in the transfected cells. The filled bars represent mean values, the bracket above each bar indicates one standard deviation. 


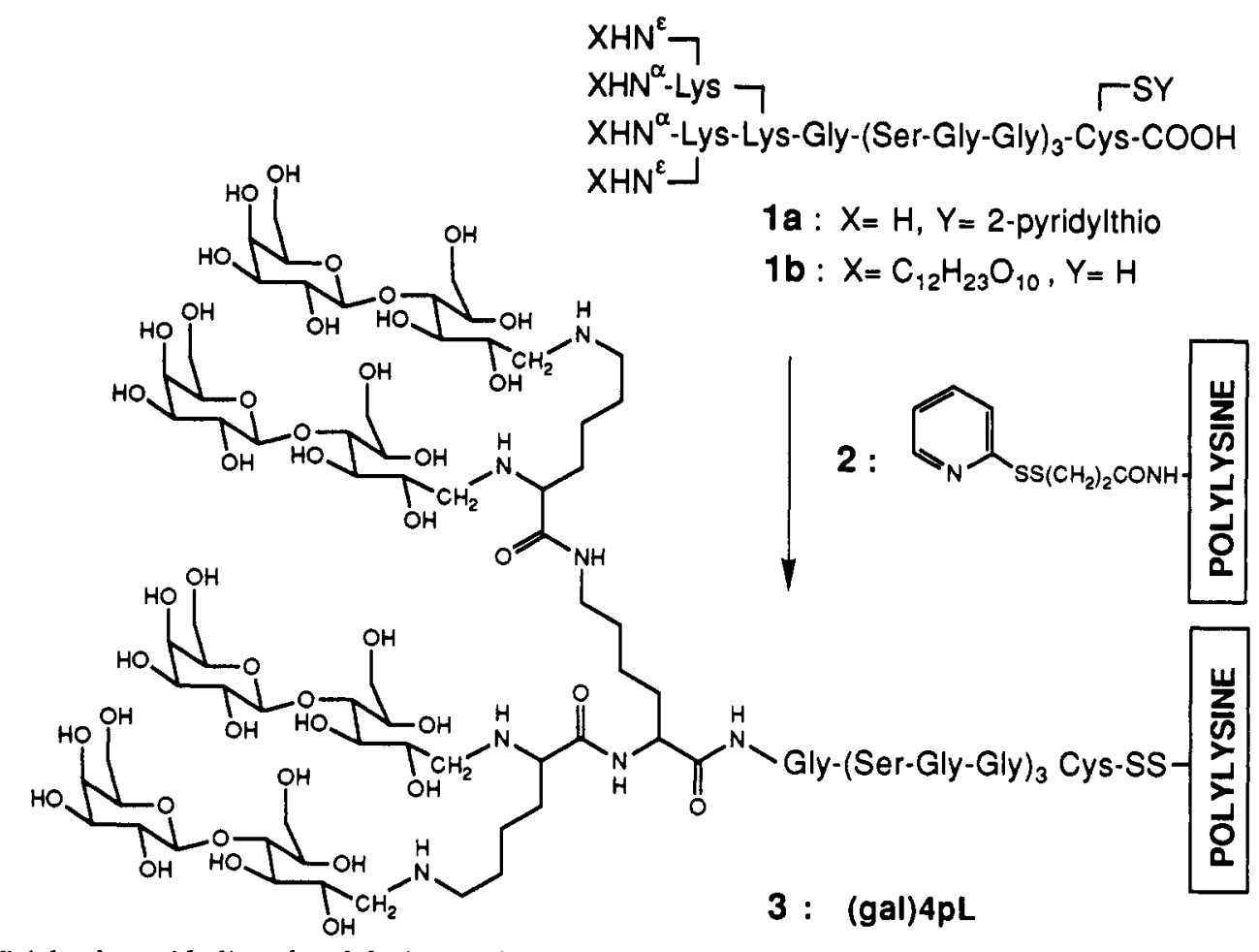

Figure 1. Artificial galactoside ligand-polylysine conjugate.

\section{RESULTS}

Synthesis. We wanted to construct a tetra-antennary ligand containing four galactoside residues that should serve for binding to the asialoglycoprotein receptor. For this purpose, the branched peptide la (see Figure 1) was prepared by automated solid-phase synthesis using the Fmoc procedure (18). Branching at the $\mathrm{N}$-terminus was the result of coupling two lysines to the $\alpha$ - and $\epsilon$-amino groups of a further lysine, utilizing a concept similar to that described for the preparation of MAPs (multiple antigenic peptides, ref 22). The four amino groups of 1a were modified with lactose ( $0.6 \mathrm{M}$ lactose, i.e. 12 equiv/ peptide; $37{ }^{\circ} \mathrm{C}$ ) by aldimine formation followed by reduction with sodium cyanoborohydride to the secondary amines. The resulting glycopeptide $1 \mathbf{b}$, containing the clustered carbohydrate groups separated from a C-terminal cysteine by a 10 amino acid long Gly/Ser spacer sequence, was isolated in the reduced, sulfhydryl-containing form. Modification of all four amino groups was indicated by a ninhydrin assay and confirmed by proton NMR analysis and time-of-flight mass spectroscopy. The C-terminal cysteine served for coupling to pyridyldithiopropionatemodified polylysine 2 (average chain length of ca. 290 L-lysine monomers per molecule) via disulfide bond formation in the next step. Conjugate 3, "(gal)4pL", was isolated by ion-exchange chromatography and characterized by determination of lysine and carbohydrate content. The conjugate contains, on average, 8 glycopeptide ligands per polylysine chain, which corresponds to 1 ligand per 36 lysine residues.

As reference compounds, asialofetuin-polylysine conjugates, $\mathrm{AFpL}$, and $\mathrm{N}$-lactosylated polylysine, pLyslactose, were synthesized (see Experimental Procedures). The synthesis of AFpL conjugates involved the modification of one to two amino groups on the asialofetuin molecule with succinimidyl 3-(2-pyridyldithio)propionate, followed by ligation to similarly modified polylysine 2 through the formation of disulfide bonds. $\mathrm{N}^{\epsilon}$-Lactosylated polylysine was prepared by reductive coupling of lactose to the polylysine amino groups. The chosen conditions
( $0.6 \mathrm{M}$ lactose, corresponding to 3 equiv of lactose/amino group, $37^{\circ} \mathrm{C}, 60 \mathrm{~h}$ ) resulted in modification of ca. $75-80 \%$ of the $N^{t}$-lysine amino groups.

Gene Transfer to Hepatocyte Cultures. We tested whether DNA complexed with (gal)4pL would be bound by and internalized into cells expressing the hepatocytespecific asialoglycoprotein receptor. Different DNA transport complexes were prepared by mixing plasmid DNA pRSVL [encoding $P$. pyralis luciferase as a reporter gene, under the control of the Rous sarcoma virus long terminal repeat enhancer/promoter (14)], with either (gal) $4 \mathrm{pL}$ or various other ligand-polylysine conjugates. Under these conditions the polylysine moiety of the conjugates neutralizes a large proportion (ca. 50-100\%) of the DNA charge (see the legend of Figure 2). These complexes were applied onto HepG2 cells (which express high levels of the asialoglycoprotein receptor); the cells were harvested 24 $\mathrm{h}$ later and assayed for luciferase activity. Expression of luciferase (Figure 2), as an indication of successful gene transfer into HepG2 cells, was found using transferrin, asialofetuin, or the artificial galactose-containing peptide as ligands (Figure 2, lanes 1-3), but only if the cells were also incubated in the presence of the lysosomatropic agent chloroquine, which prevents acidification and activation of lysosomal degradative enzymes, but may also act by osmotic destabilization of intracellular acidic vesicles upon internal accumulation of the agent $(2-3,8,23)$. The highest luciferase activities have been obtained with the asialofetuin conjugates (Figure 2, lane 2) and the synthetic (gal)$4 \mathrm{pL}$ conjugates (Figure 2, lane 3). Proper structural arrangement of the galactosides on the ligand seems to be essential for gene transfer. DNA complexed with lactosylated polylysine (pLys-lactose, see Experimental Procedures) was not expressed at significant levels (Figure 2, lane 4). DNA complexes containing neutralizing or slightly higher amounts of unmodified polylysine (Figure 2, lane 5) show low, but significant, receptor-independent uptake into HepG2 cells. This unspecific effect of polylysine has been observed in certain adherent cell lines in experiments at low ( $2 \%$ or less) serum levels. 


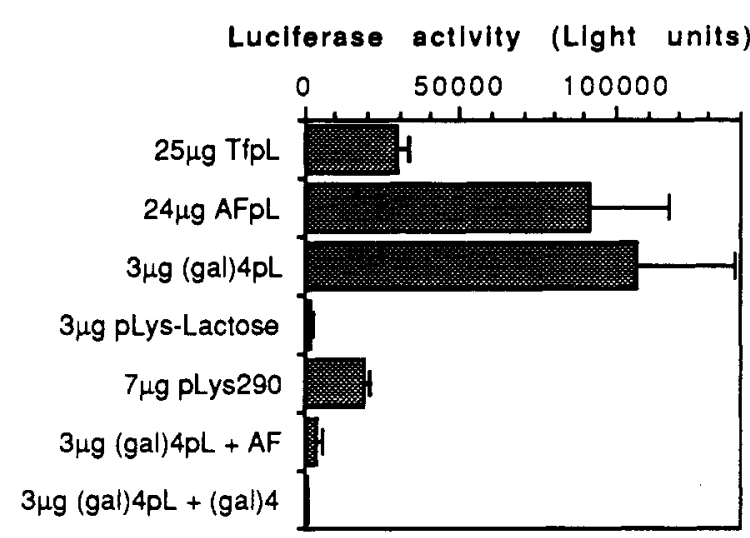

Figure 2. Luciferase gene delivery to HepG2 cells using different ligand-polylysine conjugates. pRSVL DNA $(10 \mu \mathrm{g})$ in $330 \mu \mathrm{L}$ of HBS was mixed with the indicated amounts of TfpL190B conjugate, asialofetuin-polylysine $\mathrm{AFpL}$, polylysine $\left(\mathrm{pLys}_{290}\right)$, or (gal) $4 \mathrm{pL}$, in $170 \mu \mathrm{L}$ HBS. Optimum ratios of DNA/conjugate have been determined in preliminary titrations by assaying the resulting gene-transfer efficiency (data not shown). The amounts $(\mu \mathrm{g})$ of conjugate or polycation refer, in the case of $\mathrm{pLys}_{290}$ or (gal) $4 \mathrm{pL}$, to the content of polylysine calculated as hydrobromide salt and, in the case of TfpL (or AFpL), to the transferrin (asialofetuin) content. In the competition experiments $240 \mu \mathrm{g}$ (13 equiv) of asialofetuin (AF) or $30 \mu \mathrm{g}$ ( 25 equiv) of lactosylated peptide (gal) 4 was added after $30 \mathrm{~min}$. The DNA complex mixture was then added to HepG2 cells (400 000 cells per flask) in $4 \mathrm{~mL}$ of medium containing $10 \%$ FCS; just prior to transfection, chloroquine (Sigma) was added to a final concentration of 100 $\mu \mathrm{M}$ in the transfection medium. The cells were incubated at 37 ${ }^{\circ} \mathrm{C}$ for $4 \mathrm{~h}$, and then the transfection medium was replaced by $4 \mathrm{~mL}$ of fresh DMEM plus $10 \%$ FCS. Harvesting of cells and luciferase assays were performed $24 \mathrm{~h}$ after transfection as previously described (1). Light unit values as shown represent the total luciferase activity of the transfected cells. The filled bars represent mean values; the bracket above each bar indicates one standard deviation.

We next asked if the delivery of DNA/(gal) $4 \mathrm{pL}$ complexes truly involved interactions with the asialoglycoprotein receptor. If this is the case, including excess levels of free ligand [either (gal)4 peptide or asialofetuin] should compete with DNA complexes for receptor binding and lower the subsequent luciferase gene expression. We found that inclusion of either excess free asialofetuin or free (gal)4 peptide blocks luciferase gene delivery to these cells (Figure 2 , lanes 6 and 7 ) indicating that gene delivery occurs by binding to the asialoglycoprotein receptor. In this experiment, where only half of the DNA charge was neutralized by (gal) $4 \mathrm{pL}$ conjugates, the unspecific effect of polylysine (compare Figure 2, lane 5) has been largely eliminated.

Augmentation of Gene Delivery by ReplicationDefective Adenovirus Particles. Gene transfer into the murine embryonic hepatocyte line BNL CL.2 is shown in Figure 3. Again, complexes containing the hepatocytespecific ligands, AF or (gal)4, showed the highest gene transfer activities in the presence of chloroquine (Figure $3 \mathrm{~B})$. In the absence of chloroquine only modest expression levels (Figure 3A) near the background of 150-200 light units were obtained. Although the plasmid DNA pCMVL, containing the $P$. pyralis luciferase gene under control of the more efficient cytomegalovirus immediate-early promoter/enhancer, was used, the transfection efficiencies have been moderate even in the presence of chloroquine. An alternate measure to prevent accumulation of the delivered DNA in intracellular vesicles is the use of replication-defective adenoviruses, which, as a result of their endosome-disrupting activity, have been found to strongly enhance transferrin-polylysine-mediated gene transfer into HeLa cells (9). Addition of adenovirus dl312 particles to the transfection medium resulted in a strong augmentation of gene expression both in BNL CL.2 cells (Figure 3C) and HepG2 cells (data not shown). The augmentation (30-500-fold over the level of chloroquineaugmented transfections, ca. $10^{6}$-fold over the level of control transfections) was most pronounced in the case of polylysine-rich DNA complexes (Figure 3C, “(gal)4pL"), which tend to bind adenovirus particles by ionic interaction between polylysine and the acidic viral capsid proteins (our unpublished observations). DNA/transferrin-polylysine complexes which are physically linked to the virus (10) have been found to be a most efficient means for gene transfer, as colocalization of the DNA complex and virus particle in the same endosome is guaranteed.

Enhanced Gene Transfer Using DNA Complexes Containing Galactose-Ligand and Influenza Peptides. Polylysine-conjugated peptides containing sequences derived from the $\mathrm{N}$-terminus of the influenza virus hemagglutinin HA-2 subunit have been found to substantially augment transferrin-polylysine-mediated gene transfer (11). We have prepared similar complexes (Figure 4A) containing the plasmid pCMVL, the tetra-antennary galactose ligand linked to polylysine, and the polylysinemodified influenza peptide InflupL (see Experimental Procedures and ref 11). Conditions were chosen so that the ligand-polylysine conjugate neutralized half of the DNA charge and the remainder of the charge was used to load the complexes with influenza peptide-polylysine conjugate. Delivery of these complexes into BNL CL.2 hepatocytes resulted in luciferase gene expression (Figure 4B) that was significantly higher than the expression obtained with transferrin as ligand. The expression was more than 500-fold higher than in control experiments using DNA complexes lacking the influenza peptides, but containing the same amount of transferrin or (gal) $4 \mathrm{pL}$ conjugates and polylysine (Figure 4B). The activity obtained in the presence of the modified influenza peptide was ca. 10 -fold higher than that obtained with DNA/(gal)$4 \mathrm{pL}$ complexes incubated with cells in the presence of chloroquine (see Figure 3B), and ca. 104-fold higher than in the control experiment (Figure 3A).

\section{DISCUSSION}

Our aim is to develop a synthetic gene transfer system based on receptor-mediated endocytosis, a natural mechanism that is utilized for uptake of macromolecules such as proteins or viruses into cells. For this purpose, a number of groups $(4,6,24)$, including our own, have synthesized DNA-binding conjugates of proteins that are ligands for cellular receptors. When DNA complexes prepared with the iron transporter transferrin, conjugated to polycations or other DNA-binding components $(1,15)$, are incubated with cells, the complexes bind to transferrin receptors, and subsequent uptake into the cells results in expression of the gene contained on the DNA $(2,25)$. In many cases the protein conjugation chemistry is difficult to control in terms of positions and numbers of polycation ligation sites, as a consequence of multiple potential reactive groups on the large protein ligands. In the case of transferrin conjugates, a specific ligation procedure involving modification of the transferrin carbohydrate moiety has been described (15) which allows defined, site-specific polycation attachment.

Another approach to obtain structurally well-defined DNA-binding ligand conjugates is the replacement of large protein ligands by smaller, synthetic compounds that mimic ligand-binding to a receptor. For this purpose we have synthesized an artificial ligand for the asialoglyco- 
(A)

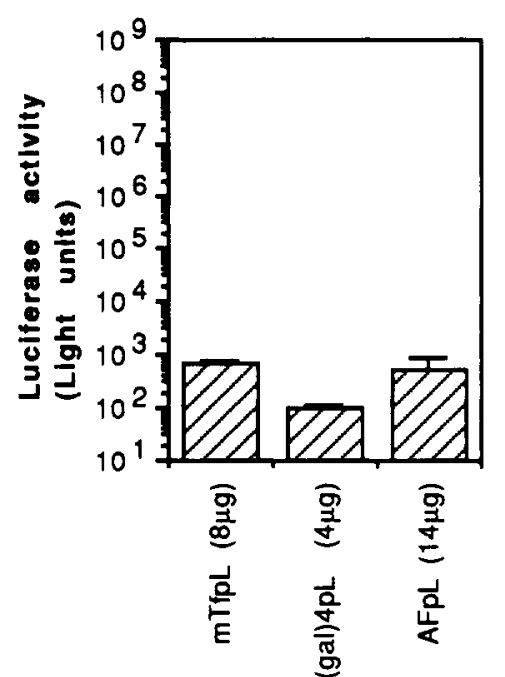

(B) +chloroquine

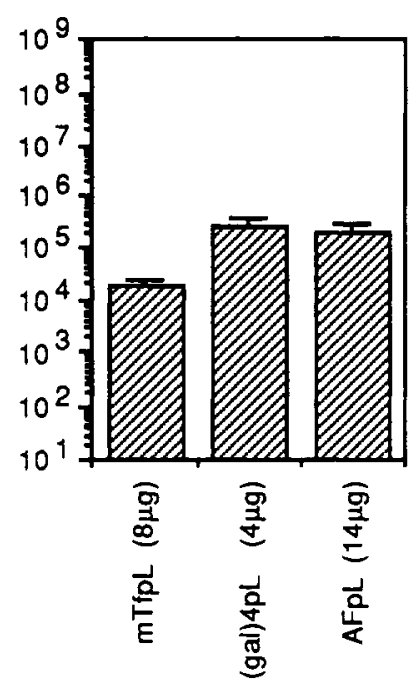

(C) +adenovirus

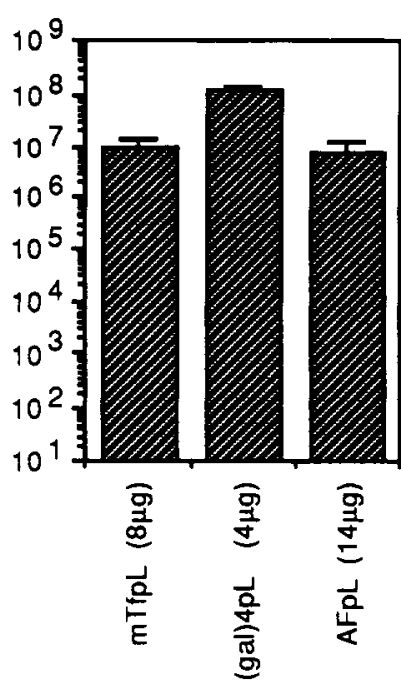

Figure 3. Transfection of BNL CL.2 hepatocytes and its augmentation by the endosome-disruption activity of defective adenovirus particles. Solutions of $6 \mu \mathrm{g}$ of pCMVL DNA in $330 \mu \mathrm{L}$ of HBS were mixed with the indicated amounts of mouse TfpL290 conjugate, asialofetuin-polylysine (AFpL), or (gal) $4 \mathrm{pL}$, in $170 \mu \mathrm{L} \mathrm{HBS}$, and left for $30 \mathrm{~min}$ at room temperature. The DNA complexes were added to BNL CL.2 cells ( 300000 cells per plate) cultured with $1 \mathrm{~mL}$ of fresh medium containing $2 \%$ FCS without (A) or with (B) chloroquine (final concentration $100 \mu \mathrm{M}$ ). Cells were incubated at $37^{\circ} \mathrm{C}$ for $2 \mathrm{~h}$, and then $1.5 \mathrm{~mL}$ of medium containing $10 \%$ FCS without (A) or with (B) $100 \mu \mathrm{M}$ chloroquine was added. Two hours later the transfection medium was replaced by $4 \mathrm{~mL}$ of fresh high-glucose DMEM plus $10 \%$ FCS. (C) Instead of including chloroquine in the cell culture medium, to each DNA/conjugate complex was added $1 \mathrm{~mL}$ of DMEM containing $2 \%$ FCS and $50 \mu \mathrm{L}$ of adenovirus dl312 stock solution (ca. $10^{9}$ viral particles). Incubation of the cells with the complexes and further manipulations were performed as described above, but in the absence of chloroquine. Assays were performed as described in Figure 2.

protein receptor. This hepatocyte-specific receptor has already proven to be suitable for gene delivery using asialoorosomucoid-polylysine conjugates (5). The interaction of this receptor with its ligand is well-studied and occurs via recognition of (preferentially) three terminal galactose residues on the asialoglycoprotein ligand by the trimeric subunits of the receptor (7). Triantennary or tetra-antennary oligosaccharides (that are present, for example, on asialofetuin or asialo-orosomucoid) with three or four terminal galactose residues are rapidly endocytosed by hepatocytes, whereas there is no evidence of efficient endocytosis of biantennary oligosaccharides (26) or asialoglycoproteins containing biantennary oligosaccharides (27). The clustering effect has also been described for the binding of neoglycoproteins containing covalently attached synthetic galactosides at various sugar densities (28). Synthetic cluster glycosides containing three galactosyl or lactosyl residues are bound to the asialoglycoprotein receptor and endocytosed by hepatocytes $(29,30)$.

We have synthesized a tetra-antennary ligand, (gal)4, containing galactoside residues bound to a branched peptide backbone which should provide appropriate structural arrangement of the carbohydrate groups (Figure 1). This synthetic ligand, if conjugated to polylysine, binds to DNA and delivers the gene contained on the DNA into cultured hepatocytes. The uptake most likely proceeds through binding to the asialoglycoprotein receptor followed by endocytosis, because the gene expression can be inhibited by addition of compounds that compete for binding to the asialoglycoprotein receptor (Figure 2).

After endocytosis, in the natural context, asialoglycoproteins are targeted to lysosomes and degraded by hydrolytic enzymes. The accumulation in lysosomal compartments may present a major limit to receptormediated gene delivery. A related hurdle seems to be present in the case of gene transfer by calcium phosphate precipitation, where over $50 \%$ of the DNA was found degraded in lysosomes (31). Nevertheless, successful receptor-mediated gene transfer has been found using asialoorosomucoid-polylysine conjugates $(5,6)$. In our hands, the expression levels in hepatocyte gene transfer experiments with asialofetuin or the (gal) 4 conjugates were very low unless further supporting measures (see below) were taken. Some rationalizations for the difference to the published data $(5,6)$ are as follows: (i) we are working with a slightly different system (ligand, conjugate, reporter gene, complex formation, amount of reagents, cell culture conditions); (ii) we believe that the gene transfer in the published system $(5,6)$ may be considerably augmented by the use of supporting agents such as chloroquine or adenovirus. In our experiments, efficient gene transfer was found when we included either chloroquine, which may protect to some extent internalized material from lysosomal degradation and/or may destabilize intracellular vesicles, or agents that promote the release of internalized DNA complexes from endosomes. A particularly effective measure consists of the use of defective adenovirus particles with endosome-disruption activity $(9,32)$, which (in comparison to chloroquine) results in a 500 -fold enhancement of gene expression mediated by the (gal)4-containing DNA complexes (Figure 3).

Instead of using whole viral particles, it would be desirable to generate completely synthetic gene transfer complexes that utilize cellular mechanisms for entry. We intended to separate the endosome-release function of viruses from the whole virus particles. In this context, we have recently demonstrated that small synthetic peptides derived from influenza virus hemagglutinin that are able to disrupt membranes specifically under acidic conditions, if included in DNA complexes, promote transferrinmediated gene transfer (11). We have shown here that DNA complexes containing both the synthetic ligand for endocytosis, (gal)4, and the synthetic membrane-active influenza peptide can deliver genes to hepatocytes with an efficiency approximately 500-fold higher than complexes lacking the influenza peptide (Figure 4), but still 
(A)

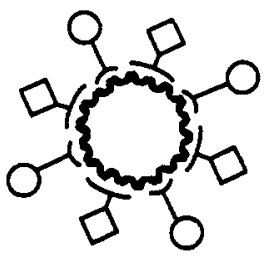

= ligand for endocytosis

e.g. tronsferrin or $($ gal) 4

= endosome-disruption agent

e.g.

amphiphatic peptides from influenza virus hemagglutinin

\begin{tabular}{|l|l|}
\hline & Luciferase activity (Light units) \\
\hline $\mathrm{TfpL}+\mathrm{pLys}$ & 1700 \\
\hline $\mathrm{TfpL}+\operatorname{InflupL}$ & $1 \times 10^{6} 2 \times 10^{6}$ \\
\hline$(\mathrm{gal})_{4} \mathrm{pL}+\mathrm{pLgs}$ & 2700 \\
\hline$(\mathrm{gal})_{4} \mathrm{pL}+\operatorname{InflupL}$ & \\
\hline
\end{tabular}

Figure 4. Gene transfer using combination complexes containing receptor ligands and membrane-active peptides. (A) Schematic drawing of DNA complexes containing both a ligand for endocytosis and a membrane-active component for endosome disruption. (B) Luciferase gene transfer into BNL CL.2 hepatocytes. DNA combination complexes were prepared by mixing first $6 \mu \mathrm{g}$ of pCMVL-DNA in $160 \mu \mathrm{L}$ of HBS with $4 \mu \mathrm{g}$ of $\mathrm{TfpL}_{290}$ or $2 \mu \mathrm{g}$ of (gal) $4 \mathrm{pL}$ in $160 \mu \mathrm{L}$ of HBS and, after 15-30 min at room temperature, subsequent mixing with $20 \mu \mathrm{g}$ of the influenza HA-2 $\mathrm{N}$-terminal peptide-poly(L-lysine) conjugate (InflupL) or with $20 \mu \mathrm{g}$ of unmodified poly(L-lysine) (pLys), in $160 \mu \mathrm{L}$ of HBS. Addition of the DNA complexes to the cells (in the absence of chloroquine) and further treatment of the cultures was performed as described in Figure 3A. Cell culture samples were harvested and assayed for luciferase activity as described in Figure 2.

approximately 50 -fold lower than with adenovirus particles (Figure 3C). Our synthetic ligand for the asialoglycoprotein receptor functions comparably to a natural ligand and, with respect to hepatocytes, even better than transferrin as ligand in gene-transfer experiments. We hope that gene-transfer systems containing synthetic, welldefined ligands such as the (gal) 4 described here, combined in a modular manner with other functional components such as synthetic membrane-disrupting peptides, will prove useful for targeted gene-transfer applications.

\section{ACKNOWLEDGMENT}

We thank Prof. Dr. Martin Spiess (Basle) for providing HepG2 cells. We also thank Helen Kirlappos for technical assistance. We thank Prof. Dr. Max L. Birnstiel for support and helpful discussions. We further appreciate the critical reading of this paper by Drs. Lisa Ballou and Berndt Oberhauser. We are grateful to Dr. Horst Ahorn for the help in preparing time-of-flight mass spectra.

\section{LITERATURE CITED}

(1) Wagner, E., Zenke, M., Cotten, M., Beug, H., and Birnstiel, M. L. (1990) Transferrin-polycation conjugates as carriers for DNA uptake into cells. Proc. Natl. Acad.Sci.U.S.A.87,34103414.

(2) Cotten, M., Langle-Rouault, F., Kirlappos, H., Wagner, E., Mechtler, K., Zenke, M., Beug, H., and Birnstiel, M. L. (1990) Transferrin-polycation-mediated introduction of DNA into human leukemic cells: stimulation by agents that affect the survival of transfected DNA or modulate transferrin receptor levels. Proc. Natl. Acad. Sci. U.S.A. 87, 4033-4037.

(3) Cotten, M., Wagner, E., and Birnstiel, M. L. (1992) Receptor mediated transport of DNA into eukariotic cells. Methods Enzymol., in press.

(4) Huckett, B., Ariatti, M., and Hawtrey, A. O. (1990) Evidence for targeted gene transfer by receptor-mediated endocytosis. Biochem. Pharmacol. 40, 253-263.

(5) Wu, G. Y., and Wu, C. H. (1987) Receptor-mediated in vitro gene transformation by a soluble DNA carrier system. J. Biol. Chem. 262, 4429-4432.

(6) Wu, C., Wilson, J., and Wu, G. (1989) Targeting genes: Delivery and persistent expression of a foreign gene driven by mammalian regulatory elements in vivo. J. Biol. Chem. 264 , 16985-16987.

(7) Spiess, M. (1990) The asialoglycoprotein receptor: A model for endocytic transport receptors. Biochemistry 29, 1000910018.

(8) Zatloukal, K., Wagner, E., Cotten, M., Phillips, S., Plank, C., Steinlein, P., Curiel, D., and Birnstiel, M. L. (1992) Transferrinfection: A highly efficient way to express gene constructs in eukariotic cells. Ann. N.Y. Acad. Sci. 660, 136153.

(9) Curiel, D. T., Agarwal, S., Wagner, E., and Cotten, M. (1991) Adenovirus enhancement of transferrin-polylysine-mediated gene delivery. Proc. Natl. Acad. Sci. U.S.A. 88, 8850-8854.

(10) Wagner, E., Zatloukal, K., Cotten, M., Kirlappos, H., Mechtler, K., Curiel, D. T., and Birnstiel, M. L. (1992) Coupling of adenovirus to transferrin-polylysine/DNA complexes greatly enhances receptor-mediated gene delivery and expression of transfected genes. Proc. Natl. Acad. Sci. U.S.A. 89, 60996103.

(11) Wagner, E., Plank, C., Zatloukal, K., Cotten, M., and Birnstiel, M. (1992) Influenza virus hemagglutinin HA-2 $\mathrm{N}$-terminal fusogenic peptides augment gene transfer by transferrin-polylysine/DNA complexes: Towards a synthetic virus-like gene transfer vehicle. Proc. Natl. Acad. Sci.U.S.A. 89, 7934-7938.

(12) Wharton, S. A., Martin, S. R., Ruigrok, R. W. H., Skehel, J. J., Wiley, D.C. (1988) Membrane fusion by peptide analogues of influenza virus haemagglutinin. J. Gen. Virol. 69, 18471857.

(13) Severne, Y., Wieland, S., Schaffner, W., and Rusconi, S. (1988) Metal binding 'finger' structures in the glucocorticoid receptor defined by site-directed mutagenesis. EMBO J. 7, 2503-2508.

(14) DeWet, J., Wood, K., DeLuca, M., Helinski, D., and Subramani, S. (1987) Firefly luciferase gene: Structure and expression in mammalian cells. Mol. Cell. Biol. 7, 725-737.

(15) Wagner, E., Cotten, M., Mechtler, K., Kirlappos, H., and Birnstiel, M. L. (1991) DNA-binding transferrin conjugates as functional gene-delivery agents: Synthesis by linkage of polylysine or ethidium homodimer to the transferrin carbohydrate moiety. Bioconjugate Chem. 2, 226-231.

(16) Ellman, G. L. (1959) Arch. Biochem. Biophys. 82, 70.

(17) Seifter, S., Dayton, S., Novic, B., and Muntwyler, E. (1950) Arch. Biochem. 25, 191.

(18) Atherton, E., Gait, M. J., Sheppard, R. C., and Williams, B. J. (1979) The polyamide method of solid phase peptide synthesis and oligonucleotide synthesis. Bioorg. Chem. 8, 351 .

(19) Atherton, E., and Sheppard, R. C. (1989) Solid Phase Peptide Synthesis, The Practical Approach Series. IRL Press, Oxford, England. 
(20) Knowles, B. B., Howe, C. C., and Aden, D. P. (1980) Human hepatocellular carcinoma cell lines secrete the major plasma proteins and hepatitis B surface antigen. Science 209, 497499.

(21) Patek, P. Q., Collins, J. L., and Cohn, M. (1978) Transformed cell lines susceptible or resistant to in vivo surveillance against tumorigenesis. Nature 276, 510-511.

(22) Tam, J. P. (1988) Synthetic peptide vaccine design: Synthesis and properties of a high-density multiple antigenic peptide system. Proc. Natl. Acad. Sci. U.S.A 85, 5409-5413.

(23) Corley Cain, C., Sipe, D. M., and Murphy, R. F. (1989) Regulation of endocytic $\mathrm{pH}$ by the $\mathrm{Na}, \mathrm{K}$-ATPase in living cells. Proc. Natl. Acad. Sci. U.S.A. 86, 544-548.

(24) Rosenkranz, A. A., Yachmenev, S. V., Jans, D. A., Serebryakova, N. V., Murav'ev, V. I., Peters, R., and Sobolev, A. S. (1992) Receptor-mediated endocytosis and nuclear transport of a transfecting DNA construct. Exp. Cell Res. 199, 323-329.

(25) Zenke, M., Steinlein, P., Wagner, E., Cotten, M., Beug, H., and Birnstiel, M. L. (1990) Receptor-mediated endocytosis of transferrin polycation conjugates: An efficient way to introduce DNA into hematopoietic cells. Proc. Natl. Acad. Sci. U.S.A. $87,3655-3659$.

(26) Baenziger, J. U., and Fiete, D. (1980) Galactose and $\mathrm{N}$-acetylgalactosamine-specific endocytosis of glycopeptides by isolated rat hepatocytes. Cell 22, 611-620.
(27) Ashwell, G., and Morell, A. G. (1974) The role of surface carbohydrates in the hepatic recognition and transport of circulating glycoproteins. Adv. Enzymol. 41, 99-128.

(28) Lee, Y. C. (1989) Binding modes of mammalian hepatic Gal/GalNAc receptors. Carbohydrate Recognition in Cellular Function. (Ciba Foundation Symposium 145) pp 80-95, Wiley, Chichester.

(29) Connolly, D. T., Townsend, R. R., Kawaguchi, K., Bell, W. R., and Lee, Y. C. (1982) Binding and endocytosis of cluster glycosides by rabbit hepatocytes. J. Biol. Chem. 257, 939945.

(30) Kempen, H. J. M., Hoes, C., van Boom, J. H., Spanjer, H. H., de Lange, J., Langendoen, A., and van Berkel, T. J. C. (1984) A water-soluble cholesteryl-containing trisgalactoside: Synthesis, properties, and use in directing lipid-containing particles to the liver. J. Med. Chem. 27, 1306-1312.

(31) Orrantia, E., and Chang, P. L. (1990) Intracellular distribution of DNA internalized through calcium phosphate precipitation. Exp. Cell. Res. 190, 170-174.

(32) Cotten, M., Wagner, E., Zatloukal, K., Phillips, S., Curiel, D. T., and Birnstiel, M. L. (1992) High-efficiency receptormediated delivery of small and large $(48 \mathrm{~kb})$ gene constructs using the endosome disruption activity of defective or chemically inactivated adenovirus particles. Proc. Natl. Acad. Sci. U.S.A. 89, 6094-6098. 